\title{
The Compound Interest Law and Plant Growth.
}

BY

\section{H. BLACKMAN.}

$\mathrm{T}$ many phenomena of nature we find processes in which the rate of change of some quantity is proportional to the quantity itself. Since money put out at compound interest increases in this way-the rate of increase being clearly proportional to the amount of capital at any timeLord Kelvin called the law which such processes follow 'the compound interest law'. The rate at which a body cools follows the compound interest law, for the hotter the body relative to its surroundings the more rapidly it loses heat. Again, the variation of atmospheric pressure with height above sea-level follows this law, as does also the velocity of a chemical reaction. Wilhelmy's law, discovered as long ago as 1850 , that 'the amount of chemical change in a given time is directly proportional to the quantity of reacting substance present in the system ', is simply a restatement of the compound interest law.

The importance of this law for the proper appreciation of the growth of a plant was brought home to the writer in I9I 7 in connexion with the results of some experiments on the growth of cucumbers carried out in association with Mr. F. Gregory at the Cheshunt Experimental Station.

It is clear that in the case of an ordinary plant the leaf area will increase as growth proceeds, and with increasing leaf area the rate of production of material by assimilation will also increase; this again will lead to a still more rapid growth, and thus to a greater leaf area and a greater production of assimilating material, and so on. If the rate of assimilation per unit area of leaf surface and the rate of respiration remain constant, and the size of the leaf system bears a constant relation to the dry weight of the whole plant, then the rate of production of new material, as measured by the dry weight, will be proportional to the size of the plant, i.e. the plant in its increase of dry weight will follow the compound interest law.

The fact that the increase in number of unicellular organisms, when not limited by external conditions, follows a regular geometric series has long been recognized. The resemblance also of the growth processes of animals and plants to an autocatalysis has been pointed out by a number of workers, as J. Loeb, W. Ostwald, Robertson, F. F. Blackman, Chodat 
and his pupils. ${ }^{1}$ The application of the compound interest law to the growth of the higher plants, though of fundamental importance to a right understanding of the plant's rate of increase, has, however, been overlooked by most botanists, ${ }^{2}$ and its recognition is sadly lacking in the textbooks both of plant physiology and general botany. Chodat in his 'Principes de Botanique' (2nd edit., p. I33) appears to be the only text-book writer who even refers to the relation of growth to a geometric series, and his treatment of the subject appears under the section of the book which deals with the growth of the cell, and it is confined to pointing out the similarity of the growth of the cell to a process resembling autocatalysis.

Apart from any question of autocatalysis it is obvious that the increase in size of the assimilating surface of the young plant must constantly accelerate the rate of growth, and that the consideration of this acceleration is essential for the proper comparison of the final weight of different plants and of the same plants grown for different periods.

When money accumulates at compound interest, the final amount reached depends on (I) the capital originally employed, (2) the rate of interest, (3) the time during which the money accumulates. In the case of an annual plant the ultimate dry weight attained will depend on (I) the weight of the seed, since that determines the size of the seedling at the time that accumulation of new material begins; $(2)$ on the rate at which the material present is employed to produce new material, i. e. the percentage increase of dry weight per day or week or other period; (3) the time during which the plant is increasing in weight.

It is clear then that some simple equation is required to relate these three factors to the final weight attained; such an equation does not appear to have been hitherto put forward by those few workers who have considered the growth relations of the whole plant from this aspect. Before dealing, however, with this attention may be drawn to the work of Noll and his pupils, who have provided the data of the growth relations of a number of plants during various stages.

Noll seems to have been the first to formulate the view that in the case of an annual plant the successive dry weights taken at regular periods follow a geometric series. In 1906 Noll read before the Niederrheinische Gesellschaft für Natur- und Heilkunde zu Bonn a paper (which appears only

1 There can be no doubt that the development of an increasing number of rapidly enlarging cells which occurs in the development of most plant organs will cause a rapid acceleration of growth, producing a curve of growth which is very similar to that of an autocatalysed reaction. A process of autocatalytic nature does not, however, explain the rapid fall in the rate of growth in the later stages of development of the human body, or the fall in the rate of growth of a plant organ which has passed its 'grand period' of growth. The growth of an annual body of a plant organ of limited size is clearly dominated by factors other than those that play their part in a simple autocatalytic process.

${ }^{2}$ Since the above was written I have seen the proof of a paper (to appear in the Annals of Applied Biology) by Dr. F. Kidd and Dr. W. West in which they point out the importance of the compound interest law. 
in title in the Proceedings of the society) entitled 'Über die Substanzquotienten pflanzlicher Entwickelungsstadien'. In the next two years three of his pupils, Gressler, ${ }^{1}$ Hackenberg, ${ }^{2}$ and Kiltz, ${ }^{3}$ published inaugural dissertations dealing with the determination of the 'Substanzquotienten' of various plants.

From these papers it becomes clear that the 'Substanzquotient' is the factor which relates the dry weight at the end of any period of growth with the dry weight at the beginning of that period. Taking Gressler's results with Helianthus uniflorus giganteus we find that in five successive weeks the average dry weight in grammes of a number of plants was $0.0454,0.147$, $0.508, \mathrm{I} \cdot 653,5 \cdot 868, \mathrm{I} 7 \cdot 33,30 \cdot 35,46 \cdot 2,66 \cdot \mathrm{I}, 88 \cdot 9$. Dividing the second by the first, the third by the second, and so on, we find that the successive weekly 'substance-quotients' were $3 \cdot 25,3 \cdot 45,3 \cdot 24,3 \cdot 56,3 \cdot 0,1 \cdot 75,1 \cdot 52,1 \cdot 4$, I.3. The successive, weekly dry weights clearly exhibit at first a progression which is approximately geometrical ; later, however, the rate of increase falls off, the series becoming an arithmetical one.

The 'substance-quotient' per week is obviously a clumsy and inaccurate method of expressing these results. What is required is some simple method of relating the plant's activity in the production of new material to time and to the initial weight of the seedling. Hackenberg and Kiltz merely state their results as 'substance-quotients' per week, but in calculating the average 'substance-quotient' over a period of many weeks Gressler treats his results as a discontinuous geometric series. The formula which would then apply is $W_{1}=W_{0}(\mathrm{I}+r)^{t}$, where $W_{1}=$ the final weight, $W_{0}=$ the initial weight, $r=$ the rate of interest, and $t=$ time. Gressler's results for Helianthus calculated in this way per week and per day are shown in columns 5 and 6 of the accompanying table.

H. uniflorus giganteus

H. namus

H. cucumerifolius nanus

H. macrophyllus giganteus

$H$. arboreus giganteus

$\begin{array}{ccc}\begin{array}{c}\text { Seedling } \\ \text { weight. }\end{array} & \text { Final } & \text { weight. } \\ \text { Grm. } & \text { Trme. } & \text { Days. } \\ & & \\ 0.0327 & 17.33 & 37 \\ 0.034^{8} & 14.805 & 37 \\ 0.00106 & 0.401 & 56 \\ 0.0241 & 6.77^{2} & 32 \\ 0.019^{2} & 14.680 & 40\end{array}$

Rate of Interest

(Discontinuous). per week. per day.
Rate of Interest

(Contimuous).

per week. per day.

$\begin{array}{rr}\text { II } 9.0 \% & \text { I } 7.00 \% \\ \text { II } 4.5 \% & \text { I } 6.36 \% \\ 74.1 \% & \text { I0.59\% } \\ \text { I } 23.4 \% & \text { I } 7.63 \% \\ \text { II } 6.1 \% & \text { I } 6.59 \%\end{array}$

Treatment of the results in this way would, however, only be satisfactory if the additional material were added discontimuously at the end of each day or week. It is obvious, however, that during the daylight period the plant is adding new material continuously, and during rapid growth the plant

1 P. Gressler: Ueber die Substanzquotienten von Helianthus Annuus. Inang. Diss., Bonn, I-29, Tables I-V, 1907 .

${ }^{2}$ H. Hackenberg: Ueber die Substanzquotienten von Cannabis sativa und Cannabis sigantea. Inaug. Diss., Bonn, I-2 7 , I908. Also Beihefte zum Bot. Centralbl., xxiv, pp. 45-64, I 908.

3 H. Kiltz : Versuche über den Substanzquotienten beim Tabak und den Einfluss von Lithium auf dessen Wachsthum. Inaug. Diss., Bonn, I 908 (seen only in abstract, Bot. Centralbl., cx, p. 455, 1909). 
is continuously, or nearly continuously, unfolding its leaves and increasing its assimilating area. The plant's increase is thus comparable rather to money accumulating at compound interest, in which the interest is added to the principal not daily or weekly, but continuously. The simple equation which best applies to the growth of active annual plants is thus:

$$
W_{1}=W_{0} e^{r t},
$$

where, as before, $W_{1}=$ the final weight, $W_{0}=$ the initial weight, $r=$ the rate of interest, and $t=$ time, and $e$ is the base of natural logarithms. ${ }^{1}$ Some of Gressler's results have been calculated on this basis of continuous addition at compound interest, and are given in the last two columns of the table. The rate of interest required to give the same final dry weight is naturally less when it is added continuously than when it is assumed to be added discontinuously, and far less than the rate of interest per week calculated from the weekly 'substance-quotients'.

As has already been stated, it is obvious from general considerations, and also from the equation, that the final weight attained will depend on the initial weight, the rate of interest $(r)$, and the time. The differences in the dry weight attained by two plants may thus depend on simply the initial dry weights of the seedlings; if the rate of interest is the same the final weights will then vary directly as the initial weights. This shows the marked effect which large seeds as compared with small seeds may have on the final weight attained. Again, if the initial weights are the same a small difference in the rate of interest $(r)$ will soon make a marked difference in the total yield, and the difference will increase with the lengthening of the period of growth. A difference of I per cent. in the rate of interest will in a period of 69 days double the final weight attained.

Oats in water culture may, according to Wolff, attain a dry weight 2,359 times that of the seed. If the growing period be taken as 100 days, the rate of interest on the basis of continuous addition is 7.76 per cent. per day. If the rate of assimilation per unit area should rise by $5^{\circ} 8$ per cent. then, allowing to per cent. for loss of respiration, the final weight at the end of 100 days would go up 50 per cent. Plants of Helianthus macrophyllus giganteus (investigated by Gressler) with a seed weight of 0.0241 grm. may in $3^{2}$ days reach a dry weight of 6.77 grm., i.e. a weight 251 times that of the seed. This on calculation by the equation given above requires that $r$ shall be 0.1763 (i. e. an average rate of 17.63 per cent.) per day. An increase

1 This formula can be expressed as $\log _{e} \frac{W_{1}}{W_{0}}=r t$. In tising the formula it is only necessary to find the number which expresses the relation between the final and initial dry weights of the plant ; and then to find the napierian $\log$ arithm $\left(\log _{e}\right)$ of that number, or to find the common logarithm and multiply by 2.3026 . The logarithm so found when divided by the time gives the rate of interest required. Suppose a plant has donbled itself in ten days. We find that the $\log _{e} 2$ is 0.69315 ; therefore the plant has been producing new material at the rate of 0.0693 (i. e. 6.93 per cent.) per day. If the period were 5 days the rate would be ${ }_{1} 3 . S$ per cent. per day; if 100 days, then 0.69 per cent. per day. 
of assimilation of 2 per cent. would in this case increase the weight at the end of 32 days by about 20 per cent.

A marked difference in the rate of interest $(r)$ is exhibited by different plants. The table given shows that in some species of Helianthus it may reach $\mathrm{I} 7.6$ per cent. per day, while in $H$. cucumerifolius namus it is only I0.42 per cent. per day. In some results obtained by Stefanowska ${ }^{1}$ with Maize in water culture the plants increased their fresh weight 27.5 times in 45 days; the rate of interest was therefore only $7 \cdot 45$ per cent. per day. Obviously some plants can work with far greater economy than others. Thus for every $100 \mathrm{grm}$. of dry material already present $H$. macrophylhus giganteus can produce new material at the average rate of $10.4 \mathrm{grm}$. per day ; calculating from Hackenberg's results, we find that Cannabis gigantea may work at a rate of I 3 . I per cent. per day for a short time, and (from Kiltz) that Nicotiana Tabacum may work at the rate of 20.5 per cent. per day. Zea Mais, on the other hand, as stated above, under some conditions works at the average rate of only $7 \cdot 45$ per cent. per day.

The rate of interest ( $r$ of the equation) is clearly a very important physiological constant. It represents the efficiency of the plant as a producer of new material, and gives a measure of the plant's economy in working. The rate of interest, $r$, may be termed the efficiency index of dry weight production, since not only does it indicate the plant's growth efficiency as measured by.increase of dry material, but it also appears as an exponential term in the equation which expresses the relation between the initial dry weight, the final dry weight, and the period of growth. It may also be termed the 'economy constant' of the plant; it is of course comparable to the velocity constant of a chemical reaction.

It is suggested that in all water cultures, pot experiments, and similar experiments where dry weights are determined after a period of growth, the efficiency index should be calculated from the seed weight and the final weight attained, so that a measure of the plant's average economy of working may be obtained. ${ }^{2}$ Such a calculation will show how far a large final weight is determined by a large initial weight or by a high efficiency index.

A glance at the table given above shows that the 'dwarfness' of Helianthus cucumerifolius namus is due not only to the very small seed weight but also to the comparatively low efficiency of the plant, the efficiency index being only 0.1042 (or 10.42 per cent.) per day. This form of Helianthus is handicapped by a seed $1 / 300$ th of the weight of that of H. uniflorus giganteus, so that even if it had the same efficiency it could only attain $\mathrm{I} / 300$ of the final weight of the latter. Other things being equal, a small seed is a permanent handicap to a plant in the production of material. H.cucumerifolius nanus, in order to attain after 37 days the same

1 Comptes rendus de l'Acad. des Sciences, cxxxviii, 304-6, I904.

2 Where root parts are not available, the efficiency index can be given for the aerial parts only. The seeds should, where possible, be weighed without the testa. 
weight as $H$. uniflorus, would have to work at an efficiency of 0.2621 (i. e. 26.2 I per cent.) per day; with this high economy of working the plant would double its weight in less than three days. For the highest production of vegetative material by the single plant tiero factors are necessary-large seeds, and a high economy in working represented by a large efficiency index.

The importance of these two factors in breeding cereal crop plants should be borne in mind ; it may be possible to breed for a high efficiency index. In many crop plants the matter is of course complicated by the effect of crowding on the efficiency of the individual plant, a question which requires further analyses.

The growth is naturally affected by external conditions, being higher when conditions are favourable, but even under the same conditions there are large variations in the economy of working of different plants, so the efficiency index is certainly to a large extent a characteristic of different species and varieties. It would be of great interest to determine to what these differences in efficiency are due. They may be the result of differences in the rate of assimilation per unit area of leaf surface, of differences in the rate of respiration, of differences in the thickness of the leaves, or of differences in the distribution of material to leaves on the one hand and to the axis on the other. The larger the proportion of new material that the plant can utilize in leaf production the greater, other things being equal, should be its efficiency.

It is clear, from Gressler's and Hackenberg's results with Helianthus and Cannabis, that the efficiency of the plant is greatest at first and then falls somewhat, but the fall is only slight until the formation of the inflorescence, when there is a marked diminution in the efficency index. For Helianthus arboreus giganteus, for example, the 'substance-quotients' for successive weeks are $3 . \mathrm{II}, 3.49,3.7 \mathrm{I}, 3.06,2.59,3.03,2 \cdot 0, \mathrm{I} \cdot 5, \mathrm{I} \cdot 4, \mathrm{I} \cdot \mathrm{I}, \mathrm{I} \cdot 3$, I.3. The sudden fall from 3.03 to $2 \cdot 0$ is associated with the appearance of the inflorescence.

The observations of Gressler, Hackenberg, \&c., require repetition, for they worked with only a small number of plants and they give no idea of the experimental errors involved, though the differences in dry weight of the individual plants must have been considerable. It would be very valuable to have data for various agricultural and horticultural plants, showing the average efficiency index under various conditions. If the dry weight measurements were combined with a measurement of leaf area and leaf weight some insight could be obtained into the nature of the differences which exhibit themselves as differences in the efficiency index of different plants and as differences in the efficiency index of the same plant at different stages. ${ }^{1}$

1 If such observations were combined with an estimation of the carbon content of the root, stem, and leaf, together with some measure of the rate of respiration, the analysis could be carried still further. It is hoped to undertake this work with some agricultural plants. 


\section{Blackman.-The Compound Interest Law and Plant Growth. 359}

The fall in efficiency after the first few weeks of growth may perhaps be correlated with the mechanical relations connected with larger size. A doubling of the leaf area would require a stem of more than twice the weight to attain equal strength. Gregory ${ }^{1}$ found that with larger leaf areas the ratio of stem weight to leaf weight went up.

As the efficiency of the plant is highest in its early stages favourable conditions at that time should have a marked effect on growth. If a plant, owing to such conditions, should double its size as compared with another plant, then there is no reason why that advantage should not be retained to the end of the growing season. A ' good start' means, among other things, a larger capital to work with throughout the growing season.

Gericke, ${ }^{2}$ investigating the effect of various injuries on the growth of Helianthus anmus, showed that the removal of the cotyledons not only affected the total weight - as was to be expected, since a large portion of the plant's capital was thereby lost--but also markedly reduced the efficiency of the plant. Calculations from his weekly data of dry weights show that the efficiency index never rose above 14.24 per cent. per day as compared with the 18.46 per cent. of normal plants. It is not at all clear why the loss of the cotyledons should reduce the economy of working of the plant developed from the remaining portion, especially as the removal of one cotyledon and one of the first leaves had no such effect. It suggests that the cotyledons may contain a supply of some special material necessary for the proper development and efficiency of the plant; a possible analogy with the growth substances of animals occurs to one. The subject certainly requires further investigation.

Kiltz (loc. cit.) observed in Nicotiana a marked decrease in dry weight at the time when the seed was matured, reaching 2.98 per cent. in the case of $N$. gigantea. This might be explained by assimilation being brought to a standstill while respiration continued. The amount to be explained in this way is, however, very large, and Chodat, Monnier and Deleano ${ }^{3}$ have described a restoration to the soil of mineral matter up to 40 per cent. of the dry weight of the mature plant. Whatever its cause, the phenomenon is of importance in all experiments where the dry weight of annual plants which have reached the fruiting stage is in question.

\section{SUMMARY.}

Attention is drawn to the fact that the growth of an annual plant, at least in its early stages, follows approximately the 'compound interest law'. The dry weight attained by such a plant at the end of any period will depend on (I) the weight of the seed (or the seedling at its start),

1 Experimental and Research Station, Cheshunt, Herts., Report III, p. 24, I9I 7.

2 F. Gericke: Experimentelle Beiträge zur Wachstumsgeschichte von Helianthus anmus. Inaug. Diss., Halle, I-43, 1909 .

3 Bull. de l'Herbier Boissier, vii, 350 and 948, 1907. 
representing the initial capital with which the plant starts; (2) the average rate at which the plant makes use of the material already present to build up new material : this represents the rate of interest on the capital (material) employed; (3) the period of growth.

The plant is continually unfolding its leaves and increasing its assimilating power. Successive increases in the weight of the plant cannot therefore be treated as a discontinuous geometric series, as if the new material (interest) were added at the end of daily or weekly periods. New material is added continuously during daylight, and during rapid growth the plant is continuously, or nearly continuously, unfolding its leaves and increasing its assimilating rate. The growth of the plant more nearly approximates to money accumulating at compound interest where the interest is added continuously. The simple equation which best expresses the growth relations of active, annual plants is $W_{1}=W_{0} e^{r t}$, where $W_{1}=$ the final weight, $W_{0}=$ the initial weight, $r=$ rate at which the material already present is used to produce new material, and $t=$ time.

The term $r$ is an important physiological constant, for it is a measure of the efficiency of the plant in the production of new material; the greater $r$ is, the higher the return which the plant obtains for its outlay of material.

The rate of interest, $r$, may thus be termed the 'efficiency index' of dry weight production, for not only is it a measure of the plant's efficiency but it is also an exponential term in the equation expressing the growth of the plant. In some forms of Helianthus the average efficiency index for the period up to the formation of the inflorescence may reach 0.1763 (i e. 17.63 per cent.) per day.

It is suggested that in all experiments (such as water cultures, pot experiments) dealing with the production of vegetative material the efficiency index be calculated. The relative efficiency of different plants and of the same plant at different stages can thus be determined; also the effect on the efficiency index of various external conditions.

A small difference in the 'efficiency indices' of two plants (resulting, for example, from a slightly greater rate of assimilation or a more economical distribution of material between leaves and axis) may lead to a large difference in final weight. In oats, for example, an increase of 6 per cent. in assimilation might lead to an increase of $5^{\circ}$ per cent. in dry weight at the end of soo days.

The data of earlier workers show that the 'efficiency index' is highest in the early stages of growth, and then falls slightly. In Helianthus, Camnabis, and Nicotiana it falls sharply at the beginning of the reproductive period when the inflorescence first appears.

There is evidence that annual plants at the end of their period of growth may lose considerably in dry weight.

Imperial College of Science and Technology, LONDON. 


\section{$2 \mathrm{BHL}$ Biodiversity Heritage Library}

Blackman, Vernon H. 1919. "The compound interest law and plant growth." Annals of botany 33, 353-360.

https://doi.org/10.1093/oxfordjournals.aob.a089727.

View This Item Online: https://www.biodiversitylibrary.org/item/235681

DOI: https://doi.org/10.1093/oxfordjournals.aob.a089727

Permalink: https://www.biodiversitylibrary.org/partpdf/320263

\section{Holding Institution}

Smithsonian Libraries

\section{Sponsored by}

Biodiversity Heritage Library

\section{Copyright \& Reuse}

Copyright Status: Not in copyright. The BHL knows of no copyright restrictions on this item.

This document was created from content at the Biodiversity Heritage Library, the world's largest open access digital library for biodiversity literature and archives. Visit BHL at https://www.biodiversitylibrary.org. 